\title{
Infecção via oral por Trypanosoma evansi em animais de laboratório
}

\author{
Oral infection by Trypanosoma evansi in rats and mice \\ Aleksandro Schafer da Silva ${ }^{\mathrm{I}}$ Lilian Varini Ceolin' ${ }^{\mathrm{I}}$ Camila Belmonte Oliveira ${ }^{\mathrm{I}}$ \\ Silvia Gonzalez Monteiro"I Rovaina Laureano Doyle ${ }^{\text {III }}$
}

\begin{abstract}
- NOTA -
RESUMO

Testou-se a infecção de Trypanosoma evansi pela via oral em ratos e camundongos, através de sangue contaminado de ambas as espécies. Dez ratos e dez camundongos foram alocados em quatro grupos iguais $A$ e $B$ (ratos), $C$ e $D$ (camundongos). Os grupos $A$ e C receberam sangue contaminado de um rato e o grupo $B$ e $D$ de um camundongo, através de uma sonda. $O$ volume de sangue administrado foi de $0,2 \mathrm{ml}$, o qual apresentava uma concentração de $10^{7}$ tripanossomas $\mathrm{ml}^{-1}$. Os animais foram mantidos em temperatura e umidade constantes $\left(25^{\circ} \mathrm{C}\right.$ e $80 \%$ $U R)$, sendo realizados esfregaços sanguíneos diários para

groups $A$ and $C$ were contaminated by rat-contaminated blood; $B$ and $C$ groups by mouse-contaminated blood. The blood was given using a probe filled with $0.2 \mathrm{ml}$ of contaminated blood with $10^{7}$ trypanosomes $\mathrm{ml}^{-1}$. These animals were maintained at constant temperature and humidity $\left(25^{\circ} \mathrm{C}\right.$ and $80 \%$ UR). Dairy blood smear were done to identify the prepatent period and evolution of parasite in the circulation. In the A and B groups, the pre latency period varied from 19 to 25 days and the period of parasite detection and animals death was an average of 12.7 days. The $C$ and $D$ groups did not present infection by the parasite even when evaluated for 60 days. In conclusion, the rats had oral infection by T. evansi but this protozoan couldn't contaminate the mice by digestive path.
\end{abstract} identificar o período pré-patente e a evolução do parasita na circulação. Nos grupos A e B, o período pré-patente variou de 19 a 25 dias, e o período entre a detecção dos parasitas e a morte dos animais foi em média de 12,7 dias. Os camundongos do grupo $C$ e $D$ não apresentaram infecção pelo parasita, sendo estes avaliados por 60 dias. Os ratos foram susceptíveis a infecção por T. evansi pela via oral; entretanto, os camundongos não se contaminaram com o protozoário por via digestiva.

Palavras-chave: ingestão, Trypanosoma evansi, ratos, camundongos.

\section{ABSTRACT}

In this research, Trypanosoma evansi infection was tested in rats and mice by oral ingestion of contaminated blood. Groups of ten rats and ten mice were disposed in four experimental groups: A and B (rats), $C$ and D (mice). The
Key words: ingestion, Trypanosoma evansi, mice, rats.

Trypanosoma evansi (T. evansi) é um hemoprotozoário flagelado, digenético, que se encontra na corrente sanguínea na forma tripomastigota, sendo conhecido por causar infecção em vários hospedeiros mamíferos. O parasita tem distribuição geográfica ampla, sendo responsável por causar doença significativa em animais de áreas de clima tropical, especialmente na África e América latina (LUN \& DESSER, 1995; SILVA et al., 2002).

Esse flagelado é observado como parasita do sangue de cavalos, camelos, burros, bovinos, zebuínos, caprinos, suínos, cães, búfalos, elefantes,

\footnotetext{
ICurso de Medicina Veterinária da Universidade Federal de Santa Maria (UFSM), Santa Maria, RS, Brasil.

IIDepartamento de Microbiologia e Parasitologia, Centro de Ciência da Saúde (CCS), UFSM. Faixa de Camobi, Km 9 Campus Universitário, Prédio 20, Sala 4232, 97105-900, Santa Maria, RS, Brasil. E-mail: sgmonteiro@uol.com.br. Autor para correspodência.

IIIPrograma de Pós-graduação do Curso de Medicina Veterinária, UFSM, Santa Maria, RS, Brasil.
} 
capivaras, quatis, antas, veados e pequenos roedores silvestres (SILVA et al., 2002), porém os humanos eram considerados refratários à infecção por T. evansi (KUBIAK \& MOLFI, 1954), até o relato do primeiro caso por JOSHI et al. (2005).

Os tripomastigotas presentes na circulação de vertebrados são adquiridos pelo inseto durante repasto sangüíneo, sendo responsabilizados principalmente os tabanídeos e as moscas como Stomoxys, Musca e Haematobia pela disseminação do T. evansi (SILVA et al., 2002; JONES et al., 1997).

A via oral pode ser importante na dispersão de infecção de $\boldsymbol{T}$. evansi em cachorros, quatis e capivaras, que podem ser infectados em conseqüência das brigas freqüentes entre animais infectados e não infectados. Além disso, espécies gregárias como coatis e capivaras tem um comportamento agressivo que pode transmitir o protozoário entre eles, pela via oral, mantendo a infecção no grupo social, já que a forma crônica da doença causada por T. evansi foi identificada principalmente em capivaras (Hydrochaeris hydrochaeris) e quatis (Nasua nasua) (HERRERA et al., 2004).

JANSEN (1942) avaliou as vias de inoculação por Trypanosoma equinum, sinônimo do T. evansi (HOARE, 1972), e observou resultados positivos para os seguintes animais: cães (via subcutânea, ocular e oral), cobaias (via subcutânea e ocular), camundongos (via subcutânea e peritonial), ratos e gambás (via subcutânea). Entretanto, hamster, pombo e galo foram refratários ao parasita. As vias vaginal e cutânea não foram passíveis de contaminação em cobaias. Este trabalho teve finalidade de avaliar a possível contaminação pela via oral, de ratos e camundongos com Trypanosoma evansi.

O experimento foi realizado no Laboratório de Parasitologia Veterinária da Universidade Federal de Santa Maria (UFSM), nos meses de agosto a dezembro 2005. A cepa do Trypanosoma evansi utilizada no trabalho é oriunda de cães naturalmente infectados do município de Uruguaiana, RS (COLPO et al., 2005). Os ratos (Rattus norvegicus) e camundongos (Mus musculus) machos inoculados foram tratados com anti-helmíntico à base de piperazina a $36 \%$, na dose recomendada pelo fabricante, por 15 dias antes de iniciar o experimento, sendo alimentados com ração comercial para ratos e água ad libidum.

Foram utilizados 20 animais divididos em quatro grupos iguais, A e B (cada um com cinco ratos) e C e D (com cinco camundongos cada), que receberam 0,2ml de sangue cada, via oral, através de sonda, em uma concentração do parasita de $10^{7}$ tripanosoma $\mathrm{ml}^{-1}$. Os grupos A e C receberam sangue via oral do rato e os roedores do grupo B e D ingeriram sangue do camundongo. Os animais foram mantidos em temperatura e umidade constantes $\left(25^{\circ} \mathrm{C}\right.$ e $\left.80 \% \mathrm{UR}\right)$.

Após a inoculação dos parasitas, os animais foram avaliados diariamente a fim de detectar o período pré-patente (período entre o momento da inoculação e a detecção do parasita na circulação), a longevidade dos animais inoculados e o grau de parasitemia final, através da pesquisa microscópica dos esfregaços de sangue. Após a desinfecção da região com algodão embebido em álcool iodado, foi feita a perfuração da pele da região mediana da cauda com agulha hipodérmica estéril, de onde foi coletada uma gota de sangue diretamente sobre lâmina de vidro deslisada sobre superfície da cauda, formando o esfregaço. Após a secagem, estes foram corados por Panótico Rápido® e levado ao microscópio de luz para pesquisa dos hemoparasitas ao aumento de 1.000 vezes.

Todos os ratos adquiriram a infecção pelo T. evansi pela via oral, sendo que nos grupos A e B o protozoário apresentou um período pré-patente médio de 21,8 e 21,4 dias, respectivamente (Tabela 1), período este semelhante nestes dois grupos, apesar de o sangue ingerido ser oriundo de espécies de roedores diferentes. No estudo de RAINA et al. (1985), a infecção ocorreu em $90 \%$ dos ratos, através da ingestão de $1 \mathrm{ml}$ de sangue na concentração de $2 \times 10^{4}$ de T. evansi ml-1, tendo o período pré-patente variado entre 2 a 10 dias. QUEIROZ et al. (2001) e OLIVEIRA et al. (1989) relataram que, pela via peritonial, o período pré-patente é de 1,5 dias e 5,66 dias, respectivamente; entretanto, este período pode levar até 30 dias em ratos (JANSEN, 1942). Já o presente estudo apresentou um período pré-patente maior nos animais do experimento em relação ao trabalho citado anteriormente, possivelmente devido à adaptação dos tripomastigotas aos ratos em conseqüência dos repiques da cepa que é mantida em Rattus norvegicus no laboratório, além da via de infecção ser diferente.

Os ratos infectados apresentaram em média 125,5 tripanossomas campo ${ }^{-1}$ na última análise antes da morte do animal, sendo a média do grupo A de 125 e a do B de 126 tripanossomas campo-1. O período entre a detecção dos parasitas na circulação e a morte dos animais nos grupos Ae B foi em média de 12,4 e 13 dias, respectivamente (Tabela 1). RAINA et al. (1985) relataram que ratos morreram com uma parasitemia de 20 tripanossomas campo ${ }^{-1}$. OLIVEIRA et al. (1989), em seu trabalho, obtiveram o mesmo curso de parasitemia semelhante ao deste trabalho, apesar de a via de infecção ser intraperitonial, e os animais apresentarem uma parasitemia final de 638 a 14.5000 tripanossomas $\mathrm{mm}^{-3}$ e longevidade média de 10 dias. 
Tabela 1 - Médias e desvio padrão do período pré-patente, longevidade e parasitemia final da infecção por Trypanosoma evansi em ratos e camundongos.

\begin{tabular}{|c|c|c|c|c|}
\hline Grupo & & Período Pré-patente (dias) & Longevidade (dias) & $\begin{array}{c}\text { Parasitemia final } \\
\text { (tripomastigotas/campo) }\end{array}$ \\
\hline A & Ratos & $21,8( \pm 1,48)$ & $12,4( \pm 0,89)$ & $125( \pm 17,64)$ \\
\hline B & Ratos & $21,4( \pm 2,68)$ & $13( \pm 1,41)$ & $126( \pm 25,57)$ \\
\hline $\mathrm{C}$ & Camundongos & $0( \pm 0)$ & $0( \pm 0)$ & $0( \pm 0)$ \\
\hline $\mathrm{D}$ & Camundongos & $0( \pm 0)$ & $0( \pm 0)$ & $0( \pm 0)$ \\
\hline
\end{tabular}

Os resultados mostram que não houve diferença na infectibilidade dos roedores em relação à tripanossomose, pois o grau de parasitemia final entre os ratos do mesmo grupo e degrupos diferentes foram semelhantes.

Os camundongos dos grupos C e D não apresentaram infecção pela via oral, sendo estes avaliados até 60 dias depois da administração do $\boldsymbol{T}$. evansi. FAO (1998) relata que o período pré-patente por tripanossomas africanos pode ocorrer em 24 horas após a infecção de camundongos pela via intraperitonial. Neste estudo, observou-se que camundongos inoculados pela via intraperitonial para replique da cepa de $\boldsymbol{T}$. evansi, a fim de adquirir sangue para contaminação oral, tiveram um período pré-patente de 1,5 dias, semelhante ao trabalho citado anteriomente.

JANSEN (1942), macerando carrapatos de em cães infectados com o tripanossoma e administrando via oral para camundongos e cães, não obteve infecção nos camundongos; entretanto, cinco de sete cães adquiriram a infecção pelo protozoário. Não está clara qual a causa que leva o T. evansi a infectar cães, ratos, capivaras e coatis pelo sistema digestivo. Acredita-se que este hemoparasita infecte ainda na mucosa bucal (ANGELOTTI, 1948), mas não se desconsidera que ele tenha a capacidade de invadir a mucosa gastrointestinal e chegar aos vasos sangüíneos (RAINA et al., 1985). Neste estudo, descarta-se a infecção via oral pelo T. evansi, pois o sangue foi administrado no esôfago através de uma sonda adaptada para o experimento. MENEZES (2002) relata em seu trabalho que camundongos não são um bom modelo experimental para estudar o parasita, devido aos picos inconstantes da infecção nestes animais.

A contaminação pela via oral de T. evansi em coatis e capivara pode ocorrer, assim como em cães, em conseqüência das brigas freqüentes entre infectados e não infectados (HERRERA et al., 2004). A contaminação experimental com sangue ou carne contaminada com este hemoparasita pela rota oral em cães mostrou-se positiva (RAINA et al., 1985; JANSEN, 1942). Os resultados mostram que a infecção por $\boldsymbol{T}$. evansi ocorre em ratos, mas não em camundongos.

\section{REFERÊNCIAS}

ANGELOTTI, S. Tripanosomiase. Clinical Veterinary. v.72, p.138-139, 1948.

COLPO, C.B. et al. Infecção natural por Trypanosoma evansi em cão no Rio Grande do Sul. Ciência Rural, v.35, n.3, p.717-719, 2005.

FAO - Food and Agriculture Organization of the United Nations (Programme against African Trypanosomiasis). Drug management and parasite resistance in bovine trypanosomiasis in Africa. Rome, 1998. 31p.

HERRERA, H.M. et al. Enzootiology of Trypanosoma evansi in Pantanal, Brazil. Veterinary Parasitology, v.125, p.263275, 2004

HOARE C.A. The Trypanosomes of mammals: a zoological monograph. Oxford: Blackwell, 1972. 749p.

JANSEN, G.R. Nota sobre o comportamento do Trypanossoma equinum em animais de laboratório. Revista Brasileira de Biologia, v.2, n.2, p.247-253, 1942.

JONES, T.W. et al. Trypanosoma evansi in the Republic of Indonesia. Proceedings of the first Internet Conference on salivarian trypanosomes, FOA, Animal Production and Health, 1997. p.56. (Paper n.35).

JOSHI, PP. et. al. Human trypanosomosis caused by Trypanosoma evansi in India: the first case report. The American Journal of Tropical Medicine and Hygiene, v.73, n.3, p.491-495, 2005.

KUBIAK, G.V.L.; MOLFI, A. Tripanossomíase eqüina (Mal das Cadeiras). Curitiba: Instituto de Biologia e Pesquisas Tecnológicas do Estado do Paraná. Tip. João Haupt \& Cia, 1954. p.51. (Boletim n.33).

LUN, Z.R.; DESSER, S.S. Is the broad range of hosts and geographical distribution of Trypanosoma evansi attributable to the loss of maxicircle kinetoplast DNA? Parasitol Today, v.11, p.131-133, 1995.

MENEZES, V.T. Heterogeneidade biológica e molecular de isolados de Trypanosoma evansi (Steel 1885), Balbiani 1888, oriundos do Pantanal Matogrossense. 2002. 52f. Tese (Doutorado) - Instituto Oswaldo Cruz. 
OLIVEIRA, T.C.G. et al. Comportamento do Trypanosoma evansi (T. equinum) em animais de laboratório. Arquivo Brasileiro Veterinaria e Zotecnia, v.41, n.4, p.271-277, 1989.

QUEIROZ, A.O. et al. Specific antibody levels and antigenic recognition of Wistar rats inoculated with distincts isolates of Trypanosoma evansi. Memórias do Instituto Oswaldo Cruz, v.96, n.7, p.965-972, 2001.
RAINA, A.K. et al. Oral transmission of Trypanossoma evansi infection in dogs and mice. Veterinary Parasitology, v.18, p.67-69, 1985.

SILVA, R.A.M.S. et al. Trypanosoma evansi e Trypanosoma vivax - Biologia Diagnóstico e Controle, EMBRAPA. Capturado em 15 de out. 2005. On line. Disponível na Internet: http:// www.cpap.embrapa.br/publicacoes/online/Livro015, 2002. 